Supplementary Information

\title{
Mechanistic study on the removal of $\mathrm{NO}_{2}$ from flue gas
}

\section{using novel ethylene glycol-tetrabutyl ammonium bromide}

\section{deep eutectic solvents}

Jinxiao $\mathrm{Dou}^{\dagger}$, Yongqi Zhao ${ }^{\dagger}$, Hua $\mathrm{Li}^{\dagger}, \S$, Jieping Wang ${ }^{\dagger, \&}$, Arash Tahmasebi ${ }^{\star}$, Jianglong $\mathrm{Yu}^{\dagger}$,

$\dagger$ Key Laboratory for Advanced Coal and Coking Technology of Liaoning Province,

School of Chemical Engineering, University of Science and Technology Liaoning, 185,

Qianshan Zhong Road, Anshan (114051), China

$\$$ Chemical Engineering, University of Newcastle, University Drive, Callaghan, NSW 2308, Australia

§School of Molecular Sciences, University of Western Australia, Crawley, WA 6009, Australia

${ }^{\&}$ College of Chemical Engineering, North China University of Science and Technology, Tangshan (063009), China

${ }^{*}$ Corresponding author. Tel: +61 240333902. E-mail: Jianglong.yu@newcastle.edu.au 


\section{List of Contents}

Figure S1. FT-IR spectra of EG-TBAB DESs before and after $\mathrm{NO}_{2}$ absorption at different operating temperatures. (With EG to TBAB molar ratio of $5: 1$, the residence time of $6 \mathrm{~s}$, and $\left.0.15 \% \mathrm{NO}_{2}\right)$ S3

Figure S2. FT-IR spectra of DES before and after denitrification with steam. (With operating temperature at $50{ }^{\circ} \mathrm{C}, \mathrm{EG}$ to $\mathrm{TBAB}$ molar ratio of $5: 1$, the residence time of $6 \mathrm{~s}$, and $\mathrm{NO}_{2}$ concentration of $0.15 \%)$

Figure S3. FT-IR spectra of EG-TBAB DESs before and after $\mathrm{NO}_{2}$ absorption at different oxygen partial pressures with the presence of 5\% steam. (With operating temperature at 50 ${ }^{\circ} \mathrm{C}$, EG and TBAB molar ratio of $5: 1$, the residence time of $6 \mathrm{~s}, \quad 0.15 \%$ $\left.\mathrm{NO}_{2}\right)$ 


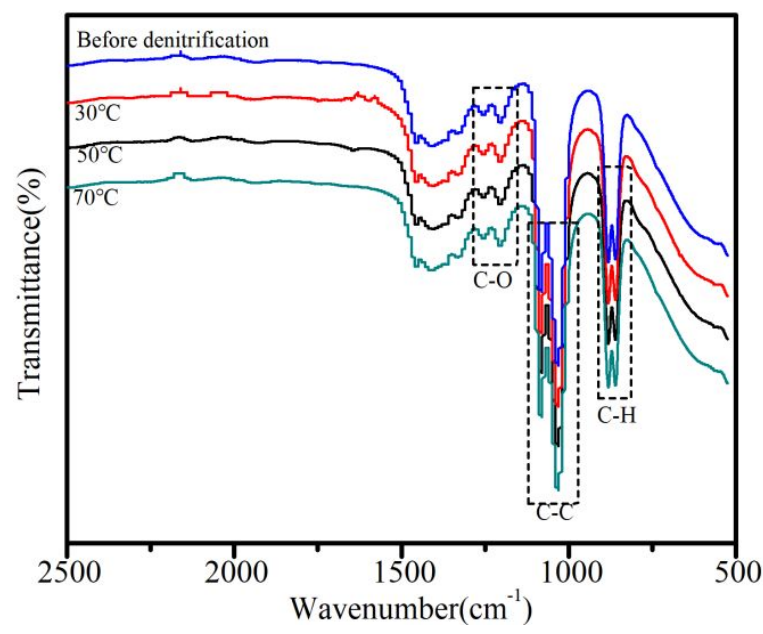

Figure S1. FT-IR spectra of EG-TBAB DESs before and after $\mathrm{NO}_{2}$ absorption at different operating temperatures. (With EG to TBAB molar ratio of 5:1, the residence time of $6 \mathrm{~s}$, and $\left.0.15 \% \mathrm{NO}_{2}\right)$

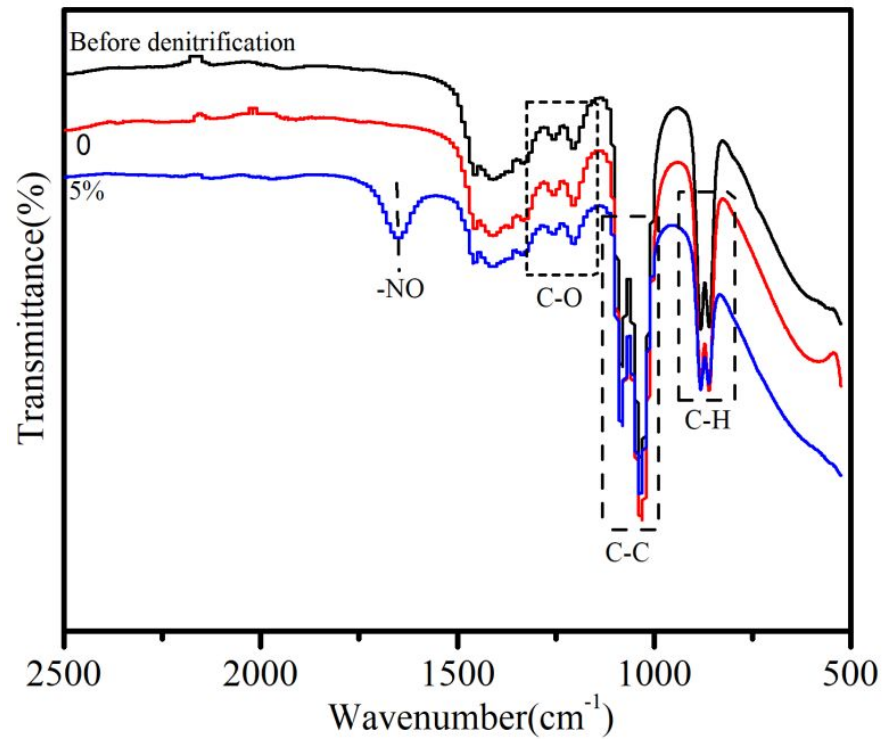

Figure S2. FT-IR spectra of DES before and after denitrification with steam. (With operating temperature at $50{ }^{\circ} \mathrm{C}$, EG to $\mathrm{TBAB}$ molar ratio of $5: 1$, the residence time of $6 \mathrm{~s}$, and $\mathrm{NO}_{2}$ concentration of $0.15 \%$ ) 


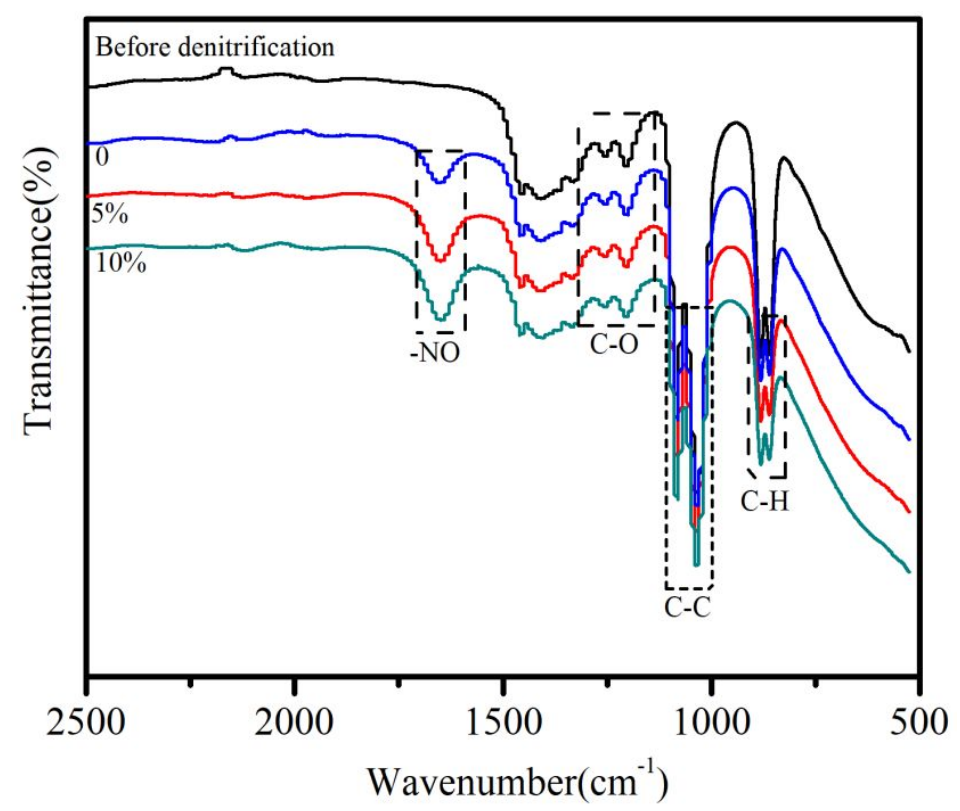

Figure S3. FT-IR spectra of EG-TBAB DESs before and after $\mathrm{NO}_{2}$ absorption at different oxygen partial pressures with the presence of $5 \%$ steam. (With operating temperature at 50 ${ }^{\circ} \mathrm{C}, \mathrm{EG}$ and TBAB molar ratio of $5: 1$, the residence time of $6 \mathrm{~s}, 0.15 \% \mathrm{NO}_{2}$ ). 